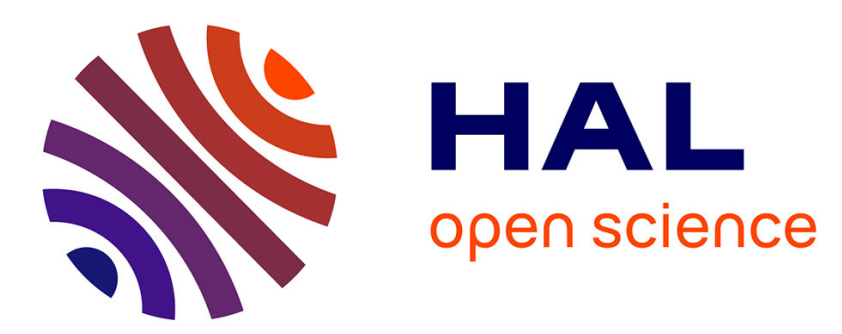

\title{
INFLUENCE OF NEIGHBOURING CHROMIUM ATOMS ON HYPERFINE FIELDS AT 57Fe NUCLEI AND ISOMER SHIFTS IN Fe-Cr ALLOYS
}

\author{
S. Dubiel, K. Krop
}

\section{> To cite this version:}

S. Dubiel, K. Krop. INFLUENCE OF NEIGHBOURING CHROMIUM ATOMS ON HYPERFINE FIELDS AT 57Fe NUCLEI AND ISOMER SHIFTS IN Fe-Cr ALLOYS. Journal de Physique Colloques, 1974, 35 (C6), pp.C6-459-C6-464. 10.1051/jphyscol:1974695 . jpa-00215852

HAL Id: jpa-00215852

https://hal.science/jpa-00215852

Submitted on 1 Jan 1974

HAL is a multi-disciplinary open access archive for the deposit and dissemination of scientific research documents, whether they are published or not. The documents may come from teaching and research institutions in France or abroad, or from public or private research centers.
L'archive ouverte pluridisciplinaire HAL, est destinée au dépôt et à la diffusion de documents scientifiques de niveau recherche, publiés ou non, émanant des établissements d'enseignement et de recherche français ou étrangers, des laboratoires publics ou privés. 


\title{
INFLUENCE OF NEIGHBOURING CHROMIUM ATOMS ON HYPERFINE FIELDS AT ${ }^{57} \mathrm{Fe}$ NUCLEI AND ISOMER SHIFTS IN Fe-Cr ALLOYS (*)
}

\author{
S. M. DUBIEL and K. KROP
}

\author{
Department of Solid State Physics, Institute of Metallurgy
}

Academy of Mining and Metallurgy, Cracow, Poland

\begin{abstract}
Résumé. - En utilisant plusieurs modèles différents on a montré que parmi les modèles en deux couches employés pour lisser les spectres Mössbauer des alliages $\mathrm{Fe}-\mathrm{Cr}$, le mieux approprié est celui qui inclut uniquement les contributions des atomes de $\mathrm{Cr}$ situés dans les deux premières sphères de coordination. Utilisant ce modèle pour lisser les spectres Mössbauer d'alliages $\mathrm{Fe}-\mathrm{Cr}$ avec différentes concentrations de chrome $(1-15$ at $\% \mathrm{Cr}$ ) on a montré que la variation du champ magnétique hyperfin au site de $57 \mathrm{Fe}\left(\Delta H_{1}\right)$ produite par une impureté dans la première sphère de coordination est supérieure à celle $\left(\Delta H_{2}\right)$ produite par une impureté qui est un second proche voisin.

Le rapport $R=\Delta H_{1} / \Delta H_{2}$ dépend de la concentration et les lissages par moindre carré de nos données montrent qu'on peut le mettre sous la forme $R=1,24+0,03 c$ pour le modèle $\mathrm{M} 12$ ou $R=1,24+0,02 c$ pour le modèle M $12 \mathrm{BW}$.

On a aussi étudié le problème de l'additivité des effets dus aux atomes de $\mathrm{Cr}$ aussi bien sur les champs magnétiques hyperfins au site des noyaux ${ }^{57} \mathrm{Fe}$ que sur les déplacements isomériques. On observe une additivité partielle et totale pour le champ magnétique hyperfin, alors que pour le déplacement isomérique il n'y a qu'une additivité totale avec d'assez grandes erreurs expérimentales.
\end{abstract}

\begin{abstract}
Using several different models it has been shown, that among the two-shell models employed for fitting the Mössbauer spectra of Fe-Cr alloys the most adequate is the one, which includes only contributions from those $\mathrm{Cr}$ atoms which occupy the first two coordination spheres. Employing then this model for fitting the Mössbauer spectra of $\mathrm{Fe}-\mathrm{Cr}$ alloys having different chromium concentration $(1-15$ at $\% \mathrm{Cr})$ it has been revealed, that the change of the hyperfine magnetic field at ${ }^{57} \mathrm{Fe}$ nuclei, $\Delta H_{1}$, due to an impurity atom in the first coordination sphere is higher than the change, $\Delta H_{2}$, due to a second-nearest neighbour impurity.

The ratio $R=\Delta H_{1} / \Delta H_{2}$ turns out to be concentration dependent and least-squeres fits to our data show that it may be expressed as $R=1.24+0.03 c$ for the M 12-model or $R=1.24+0.02 c$ for the M $12 \mathrm{BW}$-model.

The problem of the additivity of the observed effects of $\mathrm{Cr}$ atoms both on the hyperfine magnetic fields at $57 \mathrm{Fe}$ nuclei and on the isomer shifts was also investigated. For the hmf partial and total additivity is observed, whilst for the IS only total additivity occurs within rather high experimental errors.
\end{abstract}

1. Introduction. - Dilute iron alloys Fe-X, where $\mathrm{X}$ is a $3 d$ transition element are frequently used for studying hyperfine magnetic fields (hmf) at ${ }^{57} \mathrm{Fe}$ nuclei and isomer shifts (IS), employing Mössbauer effect.

In spite of many such experiments, because of the inconsistances between different investigations, a clear picture has not emerged.

The aim of our experiment was to study the influence of neighbouring $\mathrm{Cr}$ atoms on the hmf at ${ }^{57} \mathrm{Fe}$ nuclei and the IS, in Fe-Cr alloys containing 1-15 at \% of chromium. They were chosen :

1) to enhance our knowledge of such alloys and

2) because it was already known that $\mathrm{Cr}$ atoms have a pronounced effect on such hmf.

The former concerns the influence of impurity atoms, being in different coordination spheres on the

(*) Work supported by the Institute of Physics of the Polish Academy of Sciences. hmf and IS, as well as the problem of the additivity of the observed effects.

The Mössbauer effect studies on dilute Fe-Cr alloys that have been carried out so far [1-4] have revealed, that the hmf at ${ }^{57} \mathrm{Fe}$ nuclei are reduced when impurity atoms are in their vicinity. The magnitude of the hmf shifts depends on the distance between the ${ }^{57} \mathrm{Fe}$ atom involved and the impurity one. The effects due to impurities further away than the second coordination sphere are small and are usually neglected. The magnitudes of the hmf shifts due to first and second nearest neighbour impurity atoms ( $\Delta H_{1}$ and $\Delta H_{2}$ respectively) were not known. The previous results fall into three conflicting groups :

$$
\begin{aligned}
\text { I. } \Delta H_{1}>\Delta H_{2} \\
\text { II. } \Delta H_{1}=\Delta H_{2} \\
\text { III. } \Delta H_{1}<\Delta H_{2} \text {, where }
\end{aligned}
$$

$\Delta H_{1}=H(10)-H(00)$ and $\Delta H_{2}=H(01)-H(00)$. 
To give some examples, Wertheim et al. [1] have reported that $R=\Delta H_{1} / \Delta H_{2}=1.19$. Schurer [4] has found for his sample containing 3.8 at $\% \mathrm{Cr}$, that the ratio is 1.30 , which is close to the value of 1.42 reported by Cranshaw [5], obtained from his investigation of a single crystal specimen containing $4.8 \% \mathrm{Cr}$.

These results disagree with the ones obtained by Stearns [2], according to whom $\Delta H_{1}<\Delta H_{2}$.

On the other hand, Sauer and Reynik [6] as well as Vincze and Grüner [3] analysed their Mössbauer spectra assuming that $\Delta H_{1}=\Delta H_{2}$. Though such an assumption does simplify the fitting procedure, it may introduce biases to the final results when not true.

The latter reason for our choice of alloys is reflected in the well-resolved structure within the outermost lines in the $\mathrm{Fe}$ - Cr alloy Mössbauer spectra. This makes the fitting procedure easier and adds strength to interpretation of the results.

2. Experimental procedure and spectra analysis. 2.1 SAMPLE PREPARATION. - As samples 9 different chromium concentration $\mathrm{Fe}-\mathrm{Cr}$ alloys were used in the form of thin foils of 20-25 microns thickness. All the samples studied were cold-colled down to $0.1 \mathrm{~mm}$ and then electropolished [7].

2.2. EXPERIMENT. - A $10 \mathrm{mCi}$ source of ${ }^{57} \mathrm{Co}$ dissolved in palladium was used to provide monoenergetic $14.4 \mathrm{keV}$ gamma rays. The experiments were carried out with a moving source-fixed absorber geometry, using a constant-acceleration NOKIA spectrometer with an 800-channel analyser operating in the time-mode.

The Mössbauer absorption spectra obtained at room temperature with $5-13 \times 10^{5}$ counts per channel are shown in figure $1 a$ and $1 b$. The absorption in the outermost lines was as much as $\approx 13 \%$ for $c=1.28$ at $\% \mathrm{Cr}$ and $\approx 4 \%$ for $c=14.89$ at $\% \mathrm{Cr}$.

The source had a full linewidth at half maximum against an iron foil absorber of $0.26 \pm 0.02 \mathrm{~mm} / \mathrm{s}$.

2.3 SPeCtra ANALYSIS. - The spectra obtained were computer fitted, using a least-squares iteration procedure. The observed structure of the spectra was attributed to the hmf distribution in the alloys. Each spectrum was thought to be a superposition of a number of six-line Zeeman patterns, having different splittings, isomer shifts and statistical weights. It was also assumed that the lines were lorentzians and that all corresponding lines had the same width, which was, however, computer fitted.

As the grain sizes in our samples were of the order of the magnetic domain wall thickness, it is probable that the magnetic domains may comprise several grains. In such a case the magnetic anisotropic contribution to the hyperfine field will only be seen as an average, and we have not taken it into account. This effect is important in monocrystalline samples as reported recently by Schwartz and Asano [12, 13].

The number of these six-line patterns to be included
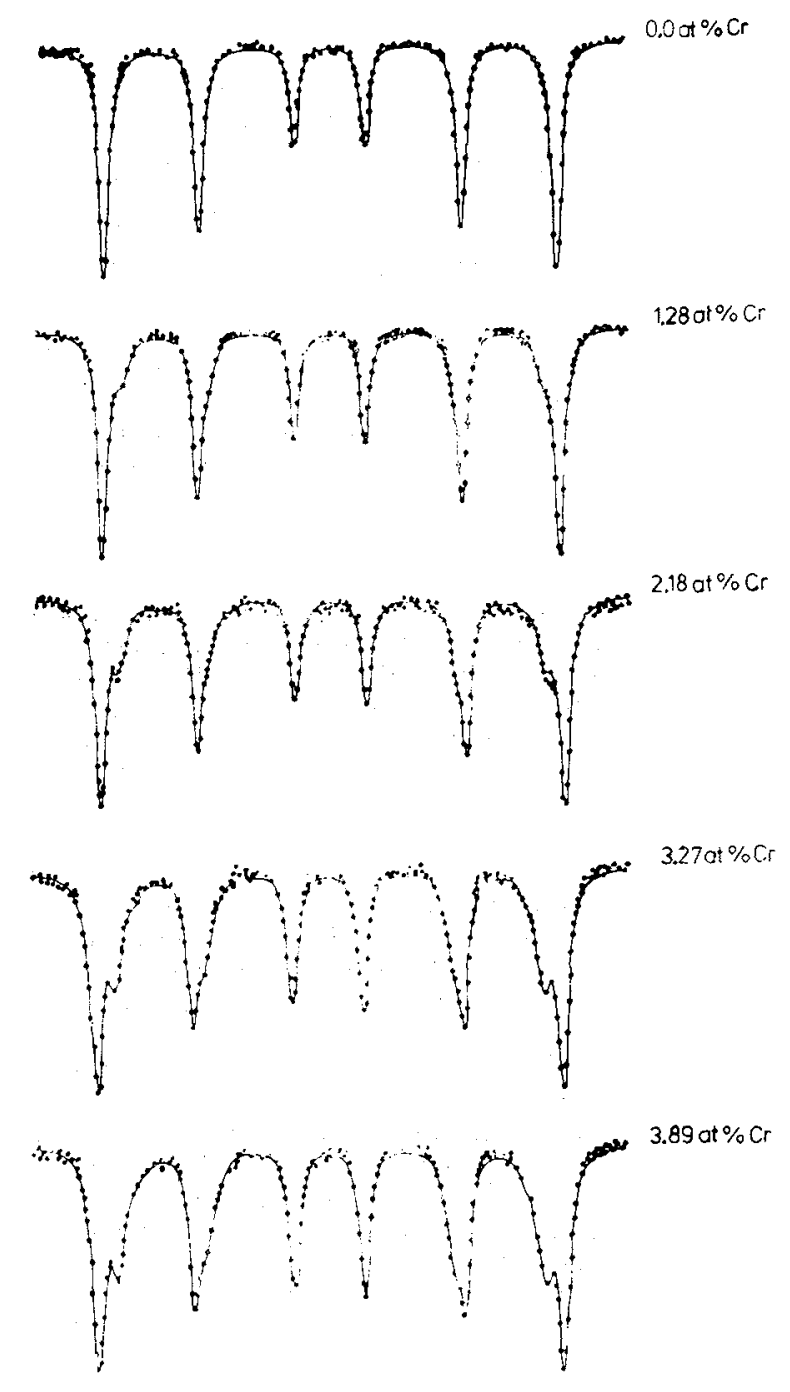

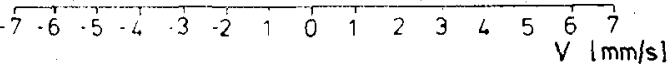

FIG. 1a. - Room temperature Mössbauer absorption spectra of Armco-Fe and $\mathrm{Fe}-\mathrm{Cr}$ alloys containing 1.28-3.89 at \% $\mathrm{Cr}$.

for a particular spectrum depends on how many coordination spheres one takes into account. Their statistical weights were calculated assuming a random impurity atom distribution in the iron lattice.

To solve the problems posed in the Introduction, the spectra were fitted on the basis of the following models :

1) M 12-model : this assumes that only effects due to the impurity atoms located in the first two coordination spheres are important.

2) $\mathrm{M} 1=2$-model : in this model it is assumed that the effects due to $\mathrm{Cr}$ atoms in the first and second coordination spheres are identical.

3) M 13-model : this attributes the observed effects to the impurities in the first and the third coordination spheres. 


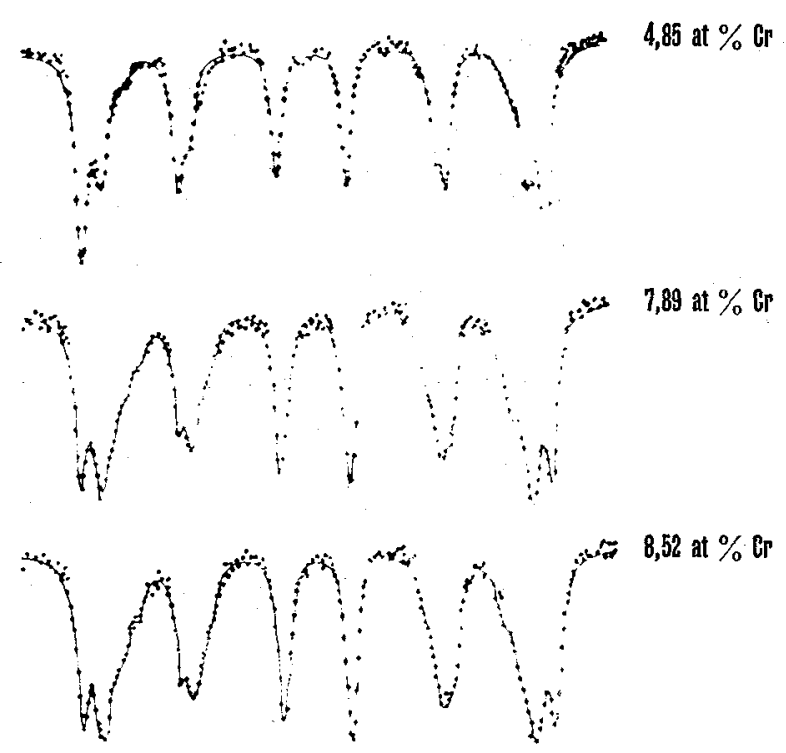

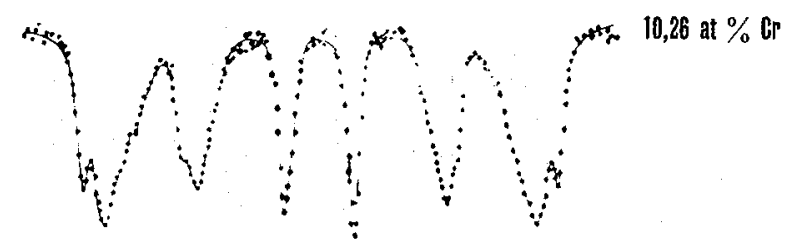

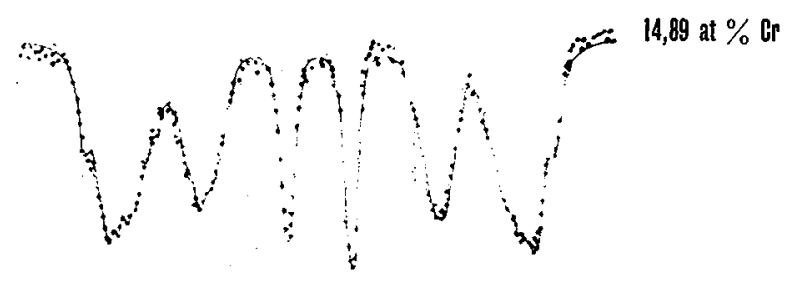

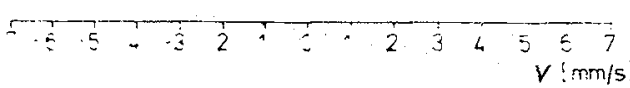

FIG. 1b. - Room temperature Mössbauer absorption spectra of $\mathrm{Fe}-\mathrm{Cr}$ alloys containing $4.85-14.89$ at $\% \mathrm{Cr}$.

4) M 123-model : this includes the effects due to the impurities located in the first three spheres.

5) M 12 BW-model : this model is similar to $\mathbf{M} 12$, but it differs in that the statistical weights of the contributing six-line patterns are parameters to be fitted. Hence it makes it possible to verify whether the assumption of random impurity distribution is valid or not.

In each model indicated above the fitting procedure included so many of the most significant contributing six-line patterns such that the overall probability of them $\geqslant 98 \%$ for all samples, except for the one containing the highest $\mathrm{Cr}$ concentration, where due to a parameter limitation of 50 , the overall probability was equal to $95 \%$.

The computer fit gave the splittings between the outermost lines for each six-line pattern from which the hmf values were obtained as well as their centres of gravity from which isomer shifts were derived.

Finally, it should be noted that in this fitting procedure no relations between the parameters were fixed.

3. Results and discussion. - 3.1 CHOICE OF THE MOST ADEQUATE MODEL. - The goodness of the fits obtained with different models was checked with chi-squared test, which gave $\chi^{2}$ values according to the following expression:

$$
\chi^{2}=S^{2} /(M-N),
$$

where

$$
S^{2}=\sum_{\mathbf{i}}\left[Y\left(x_{\mathrm{i}}\right)-\Phi\left(x_{\mathrm{i}}, p_{1}, \ldots, p_{N}\right)\right]^{2} / Y\left(x_{\mathrm{i}}\right)
$$

where :

$$
\Phi\left(x_{i}, p_{1}, \ldots, p_{N}\right)
$$

is the $N$-parameter function with one independent variable $x_{\mathrm{i}}$ to be fitted to the measured quantities $Y\left(x_{\mathrm{i}}\right)$.

$M-N$ stands for the number of degrees of freedom. It turned out that the best fits were obtained with the M 12 and M 12 BW models, as can be seen from Table I, which shows the $\chi^{2}$ values obtained from the different models. The two models gave equally good fits.

Probabilities of the six-line contributing patterns corresponding to configurations (00), (10) and (01) and calculated assuming a binomial distribution of the impurities in the iron lattice (full lines) and the ones obtained on the basis of the M $12 \mathrm{BW}$ model $(\circ, \bullet, \Delta)$ are shown in figure 2. A fairly good agreement is observed which in connection with nearly identical $\chi^{2}$ values, obtained with these two models, allows us to draw the conclusion that the assumption of random chromium atom distribution in the iron lattice is valid.

Using the other models in the fitting procedure yielded the following results :

M 1 = 2-model : the fits obtained assuming that $\Delta H_{1}=\Delta H_{2}$ are fairly good for the low concentration alloys, i. e. those containing 1.28, 2.18, 3.27 and 3.89 at $\% \mathrm{Cr}$, though they are not as good as the ones obtained from the M 12 or M 12 BW models. The spectrum of the alloy containing 4.85 at $\% \mathrm{Cr}$ could not be fitted at all (see Table I, column 4).

M 13-model : the fits yielded on the basis of this model were distinctly worse than those obtained from the M 12 or M $12 \mathrm{BW}$ models, which can be clearly seen from $\chi^{2}$ values listed in Table I, column 5 . This fact means that the suggestions proposed by some authors [8-10], namely, that an impurity atom in the third nearest neighbour shell had a stronger influence on the hyperfine interactions than one in the second nearest neighbour shell, is not valid in the case of chromium.

M 123-model : this model is certainly a better approximation to the real situation than the M 12- 
TABLE I

\begin{tabular}{|c|c|c|c|c|}
\hline at $\% \mathrm{Cr}$ & M 12 & $\mathrm{M} 12 \mathrm{BW}$ & $M 1=2$ & M 13 \\
\hline 1.28 & 2.16 & 1.97 & 2.28 & 2.38 \\
\hline 2.18 & 1.40 & 1.38 & 1.53 & 1.92 \\
\hline 3.27 & 2,86 & 2.63 & 2.96 & 5.20 \\
\hline 3.89 & 2.36 & 2.35 & 3.10 & 3.78 \\
\hline 4.85 & 2.13 & 2.11 & 13.64 & 3.72 \\
\hline 7.86 & 2.46 & 2.52 & - & 一 \\
\hline 8.52 & 2.28 & 2.48 & 一 & - \\
\hline 10.26 & 1.98 & 1.92 & - & - \\
\hline 14.89 & 2.66 & 2.70 & - & - \\
\hline
\end{tabular}

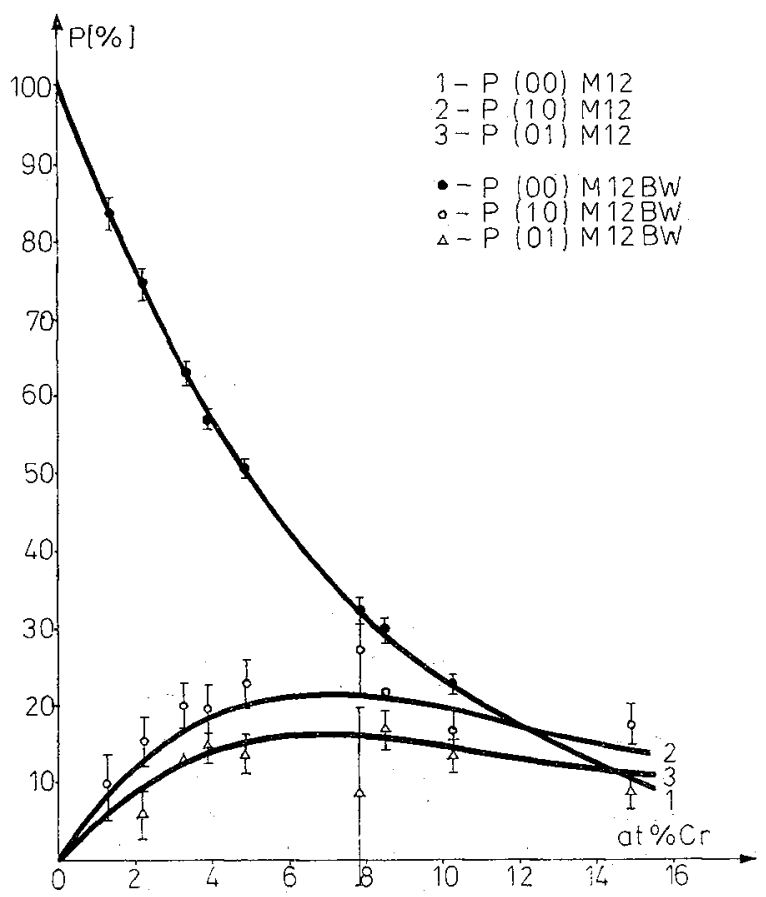

Frg. 2. - Probabilities of six-line patterns corresponding to $(00),(10)$ and $(01)$ configurations as calculated using the M 12 model (full lines) and those obtained on the basis of the M 12 BW$\operatorname{model}(\bullet, 0, \Delta)$.

model, but due to the significantly greater number of possible configurations it allows, the number of parameters to be fitted increases thereby, making the fitting procedure more complicated and decreasing the confidence level, which may be ascribed to the parameters.

In view of the above, the M 123-model has been used herein only when fitting the spectra of the alloys containing 1.28 and 3.27 at $\% \mathrm{Cr}$. This was done to find out what the magnitude of hmf shift due to a chromium atom located in the third coordination sphere is. The results indicate that :

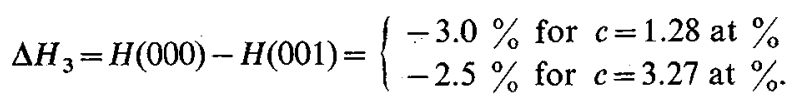

These results are in agreement with those obtained by Stearns [2], but disagree in the sign with the result received by Mendis and Anderson [8], who used the NMR technique.

In the light of the above considerations, the $\mathrm{M} 12$ (or M $12 \mathrm{BW}$ ) model has been accepted as the most adequate one and in the following the results obtained from these two models have been used.

3.2 THE INFLUENCE OF THE FIRST AND THE SECOND NEAREST NEIGHBOUR ON THE hmf AT ${ }^{57} \mathrm{Fe}$ NUCLEI. In Table II are listed values of $\Delta H_{1}, \Delta H_{2}$ and $R=\Delta H_{1} / \Delta H_{2}$ obtained using the $\mathrm{M} 12$ and $\mathrm{M} 12 \mathrm{BW}$ models. The values of the ratio $R$ are in addition shown in figure 3 , along with some results taken from the literature.

TABLE II

\begin{tabular}{|c|c|c|c|c|c|c|}
\hline \multirow{2}{*}{ at ${ }^{\mathrm{Cr}} \%$} & \multicolumn{3}{|c|}{ M $12 \mathrm{BW}$} & \multicolumn{3}{|c|}{ M 12} \\
\hline & $\Delta H_{1}$ & $\Delta H_{2}$ & $R$ & $\Delta H_{1}$ & $\Delta H_{2}$ & $R$ \\
\hline 1.28 & 29.6 & 23.0 & 1.29 & 30.4 & 23.1 & $1.32 \pm 0.23$ \\
\hline 2.18 & 32.8 & 25.8 & 1.27 & 30.6 & 23.0 & $1.33 \pm 0.23$ \\
\hline 3.27 & 31.6 & 23.1 & 1.37 & 29.4 & 24.2 & $1.21 \pm 0.21$ \\
\hline 3.89 & 32.3 & 22.5 & 1.44 & 31.1 & 22.5 & $1.38 \pm 0.24$ \\
\hline 4.85 & 31.7 & 22.3 & 1.42 & 31.5 & 22.5 & $1.41 \pm 0.27$ \\
\hline 7.86 & 30.0 & 20.0 & 1.50 & 34.3 & 23.8 & $1.44 \pm 0.27$ \\
\hline 8.52 & 33.7 & 22.4 & 1.50 & 33.0 & 21.3 & $1.55 \pm 0.27$ \\
\hline 10.26 & 31.2 & 20.9 & 1.49 & 32.7 & 20.4 & $1.60 \pm 0.27$ \\
\hline 1.89 & 0.4 & 19.2 & 1.58 & 31.9 & 19.4 & \pm 0.27 \\
\hline
\end{tabular}

Notice : hmf in kOe

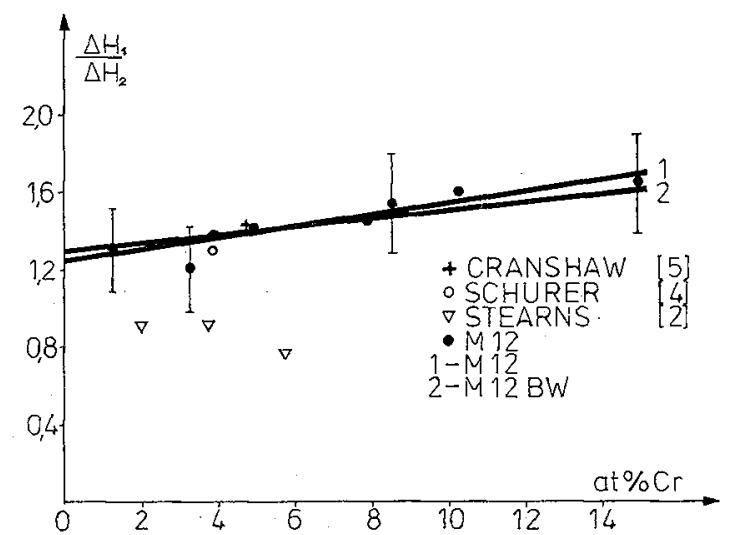

Fig. 3. - Dependence of the ratio $R$ on the chromium concentration Line 1 represents a fit to the data obtained using the $M 12$ model, while line 2 using the M $12 \mathrm{BW}$-model.

As can be seen from the figure the results obtained from these two models are identical, within the experimental errors. This confirms the validity of the assumption of a random distribution of chromium atoms in the $\mathrm{Fe}$ matrix.

The best least-squares fit to our data can be expressed as : $R=1.24+0.03 c$ for the $\mathrm{M} 12$ and $R=1.24+0.02 c$ for M $12 \mathrm{BW}$. This means that $\Delta H_{1}>\Delta H_{2}$ and is in good agreement with the results 
of Schurer [4] and Cranshaw [5], but disagrees with those of Stearns [2] and Vincze and Grüner [3].

The 2-3\% dependence of $R$ on chromium concentration is thought to reflect the influence of the $\mathrm{Cr}$ atoms that are situated further away than the first and second coordination spheres.

3.3 THE PROBLEM OF THE ADDITIVITY. - Some authors [1, 2, 11] assumed in their spectra analysis that the effects of a number of impurities in neighbouring spheres are additive. It means, that if $\Delta H_{k}$ is the hmf shift due to a single impurity atom in the $k$-th sphere, then the total hmf shift, $\Delta H$, corresponding to a particular configuration $\left(n_{1}, \ldots, n_{N}: c\right)$ is given by the relation :

$$
\Delta H\left(n_{1}, \ldots, n_{N}: c\right)=\sum_{k / 1}^{N} n_{k} \cdot \Delta H_{k}
$$

where $n_{k}$ stands for the number of impurities in the $k$-th coordination sphere and $N$ for the number of the spheres considered. The additivity described by the relation (3.3) will be called the partial additivity.

Total additivity will be also introduced by the following formula :

$$
\Delta H(c)=\sum_{\left(n_{1}, \ldots, n_{N}\right)} \Delta H\left(n_{1}, \ldots, n_{N}: c\right)
$$

where the symbol $\left(n_{1}, \ldots, n_{N}\right)$ means that summation is over all possible configurations for a given $c$.

Our studies concerning the additivity problem can be summarized in the following way. Partial additivity is obeyed, though some divergences of the order of $2-7 \%$, particulary for $(20)$ and (02) configurations are observable. Total additivity is obtained within the experimental errors, which can be seen from the values of $\Delta H(c)$ listed in Table III.

\begin{tabular}{|c|c|c|c|c|}
\hline $\begin{array}{c}\mathrm{Cr} \\
{[\text { at \%] }}\end{array}$ & $\begin{array}{c}\Delta H_{\mathrm{R}} \\
{[\mathrm{kOe}]}\end{array}$ & $\begin{array}{l}\Delta H_{\mathrm{L}} \\
{[\mathrm{kOe}]}\end{array}$ & $\begin{array}{c}\delta_{\mathbf{R}} \\
{[\mathrm{mm} / \mathrm{s}]}\end{array}$ & $\underset{[\mathrm{mm} / \mathrm{s}]}{\delta_{\mathrm{L}}}$ \\
\hline- & - & - & - & - \\
\hline 1.28 & $-52.6 \pm 5.2$ & -52.6 & $-0.0006 \pm 0.0024$ & -0.0006 \\
\hline 2.18 & $-124.6 \pm 7.1$ & -117.1 & $-0.0090 \pm 0.0044$ & -0.0070 \\
\hline 3.27 & $-108.9 \pm 4.1$ & -107.2 & $-0.0082 \pm 0.0027$ & -0.0075 \\
\hline 3.89 & $-167.2 \pm 7.2$ & -166.9 & $-0.0119 \pm 0.0035$ & -0.0081 \\
\hline 4.85 & $-237.4 \pm 8.1$ & -247.5 & $-0.0076 \pm 0.0044$ & -0.0070 \\
\hline 7.86 & $-247.7 \pm 94.3$ & -247.5 & $-0.0112 \pm 0.0162$ & -0.0009 \\
\hline 8.52 & $-298.2 \pm 28.9$ & -310.9 & $-0.0083 \pm 0.0170$ & -0.0024 \\
\hline 10.26 & $-533.7 \pm 21.0$ & -559.8 & $-0.0157 \pm 0.0120$ & -0.0141 \\
\hline 14.89 & $-667.2 \pm 65.7$ & -635.5 & $-0.0237 \pm 0.0169$ & +0.0004 \\
\hline
\end{tabular}

TABLE III

where : $\Delta H_{\mathrm{R}}$, the measured value of $\Delta H ; \Delta H_{\mathrm{L}}$, the value expected from $(3.4) ; \delta_{\mathrm{R}}$, the measured mean value of IS ; $\delta_{\mathrm{L}}$, the value expected from (3.6).

3.4 ISOMER SHIFTS. - The full results relating to the IS will be discussed in more detail in a separate publication. Here we shall refer only to the additivity.

The problem was studied in a similar way to that of the hmf. Limiting ourselves to the M 12-model, the relation of the partial additivity of the IS can be written as follows :

$$
\Delta \delta\left(n_{1}, n_{2}: c\right)=n_{1} \delta(10: c)+n_{2} \delta(01: c)
$$

while the total additivity is given by the formula :

$$
\Delta \delta(c)=\sum_{\left(n_{1}, n_{2}\right)} \Delta \delta\left(n_{1}, n_{2}: c\right) .
$$

Using the (3.5) relation, the problem of the partial additivity was studied for each possible configuration $\left(n_{1}, n_{2}\right)$, where $n_{1}+n_{2} \geqslant 2$. It has turned out from the study that this relation is not obeyed and one observes significant divergences from it.

On the other hand, relation (3.6) is, within the experimental errors, which are high, satisfied for all samples, except the one containing the highest chromium concentration (Table III).

4. Conclusions. - It has been shown that :

1) the M 12-model i. e. the model including effects for which impurities situated in the first two coordination spheres are responsible, is the most adequate amongst the two-shells models and

2) fairly good fits which could be obtained for low concentration alloys using the $\mathrm{M} 1=2$ or $\mathbf{M}$ 13models were due to the fact that the probabilities of the contributing six-line patterns calculated on the basis of these models did not differ very much from those obtained employing the M 12-model.

Using this model when fitting the observed spectra, the following conclusions could be drawn concerning the results :

a) The hmf shift, $\Delta H_{1}$, due to a single impurity atom in the first coordination sphere is evidently stronger than that, $\Delta H_{2}$, due to the second nearest one.

b) The ratio $R=\Delta H_{1} / \Delta H_{2}$ is concentration dependent, which is thought to reflect the influence of more distant $\mathrm{Cr}$ atoms neglected in the model. 
c) Total additivity of the hmf shifts is satisfied within the experimental errors, while some divergences for particular configurations, especially for (20) and (02) ones of the order of $2.7 \%$ exist. d) Total additivity of the IS is obeyed for all samples, within the high experimental errors, except for the one containing the highest $\mathrm{Cr}$ concentration. Partial additivity is, however, not satisfied.

\section{References}

[1] Wertheim, G. K.et al., Phys. Rev. Lett. 12 (1972) 24.

[2] Stearns, M. B., Phys. Rev. 147 (1966) 439.

[3] VINCZE, I. and Gr ÜNER, G., Phys. Rev. Lett. 28 (1972) 178.

[4] SChURER, P. J., Ph. D. thesis (1972), Gröningen.

[5] CRanshiaw, T. E., J. Phys. F. : Metal Phys. 2 (1972) 615

[6] SAUER, W. E. and ReYNIK, R. J., Mössbauer Effect Methodology, Vol. 4, ed. I. J. Gruverman (Plenum Press. N. Y., 1968) p. 201

[7] Dubiel, S. M., Zukrowski, J., Korecki, J., Krop, K., Acta Phys. Pol., to be published.

[8] Mendis, E. F. and Anderson, L. W., Phys. Stat. Sol. 41 (1970) 375 .
[9] Murphy, J. J. et al., J. Appl. Phys. 39 (1968) 1239.

[10] DeAN, R. H. et al., J. Phys. F : Metal Phys. 1 (1971) 78.

[11] Chandra, D. and Schwartz, L. H., Mössbauer Effect Methodology, Vol. 6, ed. I. J. Gruverman (Plenum Press, N. Y., 1971) p. 79.

[12] Asano, A., Schwartz, L. H., AIP Conference Proceedings No. 18, "Magnetism and Magnetic Materials-1973», p. 262-6, New York 1974.

[13] Schwartz, L. H., Asano, A., J. Physique Colloq. 35 (1974) C6-453. 